\title{
Numerical investigation of conveyor wing shape type effect on ocean waste collection behavior
}

\author{
Erik Sugianto ${ }^{1,2 *}$, Jeng Horng-Chen ${ }^{1}$, and Noir P. Purba ${ }^{3}$ \\ ${ }^{1}$ Department of Systems and Naval Mechatronic Engineering, National Cheng Kung University, Tainan 701, Taiwan \\ ${ }^{2}$ Department of Marine Engineering, Hang Tuah University, Surabaya 60111, Indonesia \\ ${ }^{3}$ Department of Marine Science, Padjadjaran University, Sumedang 45363, Indonesia
}

\begin{abstract}
In this paper, an attempt has been made to assess how effective waste-collecting uses the conveyor wing. This wing-equipped conveyor will later be installed in front of the ship. In this work, a simulation model is a conveyor and wing without the ship. A numerical investigation based on Reynolds Averaged Navier Stokes (RANS) for predicting the flow pattern characteristics, velocity contour, and resistance. The focus of the present study is the impact of wing shape on waste collection in calm water through the application of numerical methods. The three variations of wing shape used are solid wing shape, square hollow wing shape, and circle hollow wing shape. It is done using speed variations of 1 to 12 knots. From the analysis of velocity contour, circle hollow wing is faster in collecting waste, then followed by hollow square wing and solid wing. From the flow pattern analysis, the circle hollow wing model is easier to make ocean waste come closer to the winged conveyor than the square wing and solid wing model. It is known that winged conveyors can only be used to collect ocean waste at low speeds. Then based on resistance comparison, it is also known that the resistance of winged conveyors from the largest to the smallest is the solid wing, hollow circle wing, and hollow square wing, respectively.
\end{abstract}

\section{Introduction}

Waste in the sea, especially plastic and solid waste, are becoming global worries [1]. Plastic is sea waste majority in the Western North Pacific (33\%), Indian Ocean (31\%), and Eastern North Pacific (25\%) [2]. Floating objects like plastic can be easily transported by wind, waves, and surface currents and spread quickly in the sea [3][4]. Marine wastes have in all sizes from debris micrometres until millimetres, middle-sized wastes less than one meter long like plastic bags and soda bottles and in tens meters in length such as pieces of wrecked vessels and lost cargo containers [5]. Approximately 32 million tonnes of unmanaged plastic waste in coastal zones worldwide in 2010, producing between 4.8 and 12.7 million tonnes of plastic waste flowing from land into oceans that year. Forecasting from this condition, the total mass of plastic in 2025 will add between 100 and 250 million tonnes with the same business assumption [6]. China and Indonesia made the largest contributor to plastic waste in the sea globally, first and second in the sequence [7]. Various studies have allowed ships to play a role in collecting and processing marine debris [8]. The initial design of the monohull vessel for collecting marine debris on the island area was also proposed [9]. Including studies on the use of digital technology to involve communities around the sea to reduce marine debris [10].

Research on ships generally does not use a conveyor such as analysis of the smallest ship resistance due to differences in the shape of the catamaran hull [11]. Research on resistance and flow distribution in the ship due to differences in ship shape [12]. Research on the distance of the ship hull to the effect of ship resistance [13]. Tools or systems for collecting marine debris using conveyors are beginning to be discovered, but research on the conveyor-mounted ship is rare. Then, no study has discussed the relationship between hydrodynamics characteristics such as resistance, velocity contour, and flow patterns between conveyors and their environment.

In this paper, an attempt has been made to assess how effective waste-collecting use the conveyor wing. This wing-equipped conveyor will later be installed in front of the ship. In this work, the simulation model is conveyor and wing without the ship. A numerical investigation based on Reynolds Averaged Navier Stokes (RANS) for predicting the flow pattern characteristics that are used to analyze how easy it is for

*Corresponding author : erik.sugianto@ hangtuah.ac.id 
waste to approach the conveyor, velocity contour which is used to analyze how fast the ocean waste is approaching the conveyor, and resistance which will affect energy consumption. The focus of the present study is the impact of wing shape on waste collection in calm water through the application of numerical methods. The three variations of wing shape used are solid wing shape, square hollow wing shape, and circle hollow wing shape.

\section{Numerical Modelling}

\subsection{Conveyor and wing data}

The conveyor data used for this research are conveyors with wings. Their data is shown in Table 1.

Table 1. Winged conveyor data

\begin{tabular}{|l|r|}
\hline \multicolumn{1}{|c|}{ Type } & \multicolumn{1}{c|}{ Dimension } \\
\hline Conveyor length & $200 \mathrm{~cm}$ \\
\hline Conveyor wide & $40 \mathrm{~cm}$ \\
\hline Conveyor high & $15 \mathrm{~cm}$ \\
\hline $\begin{array}{l}\text { Angle between conveyor and } \\
\text { water surface }\end{array}$ & $25^{\circ}$ \\
\hline Wing length & $100 \mathrm{~cm}$ \\
\hline Wing high & $25 \mathrm{~cm}$ \\
\hline Wing thickness & $3 \mathrm{~cm}$ \\
\hline Immersed wing & $17 \mathrm{~cm}$ \\
\hline $\begin{array}{l}\text { Angle between wing and } \\
\text { conveyor }\end{array}$ & $45^{\circ} \mathrm{s}$ \\
\hline Speed variations & $(1,3,6,12) \mathrm{knots}$ \\
\hline
\end{tabular}

The winged conveyor model used in this study is as shown in Fig. 1. Fig. 1.a shows the front and 3D of a solid wing, Figure 1.b presents the front and 3D of the hollow square wing, and Figure 1.c presents the front view and 3D of the hollow circle wing. The main dimensions of the winged conveyor all three models are the same, but the difference is the cross-section of wing shape.

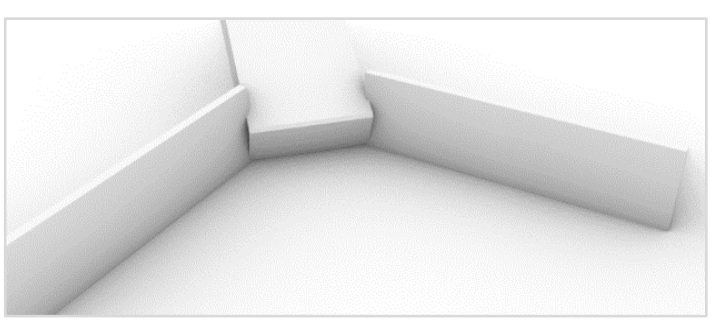

(a)

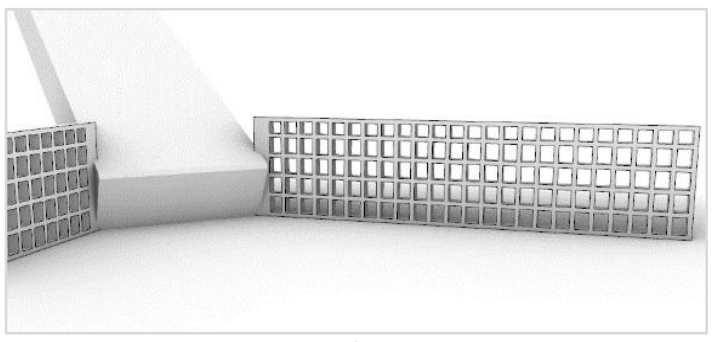

(b)

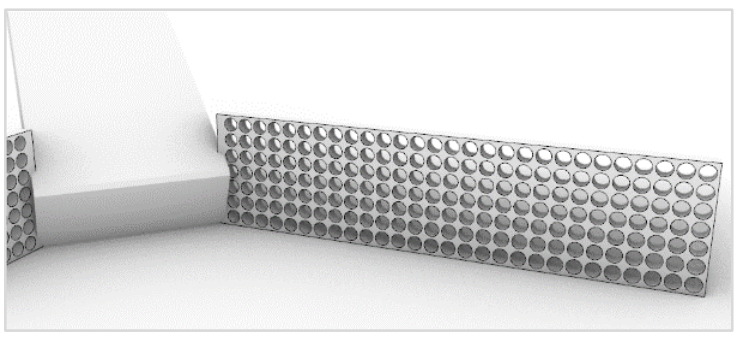

(c)

Figure 1. 3D conveyor with wings: (a) solid wing, (b) square hollow wing, and (c) circle hollow wing.

\subsection{Computational Domain}

The test was carried out on a tunnel using numerical solution methods. The winged conveyor model is covered by a $3 \mathrm{D}$ rectangular computational domain in which the flow is resolved. The computational domain is illustrated in Fig. 2, and its dimensions are expressed in terms of the overall length, L. The dimensions of the experimental tunnel are based on the recommendations of Versteeg and Malalasekera [14]. The distance from the front domain boundary to the bow is L, the distance from the stern to the rear side is $4 \mathrm{~L}$, the distance from the side of the model to the sidewall is $0.4 \mathrm{~L}$, the distance from the keel of the model to the underside is $\mathrm{L}$, and the distance from the top of the model to the sides above is $0.2 \mathrm{~L}$.

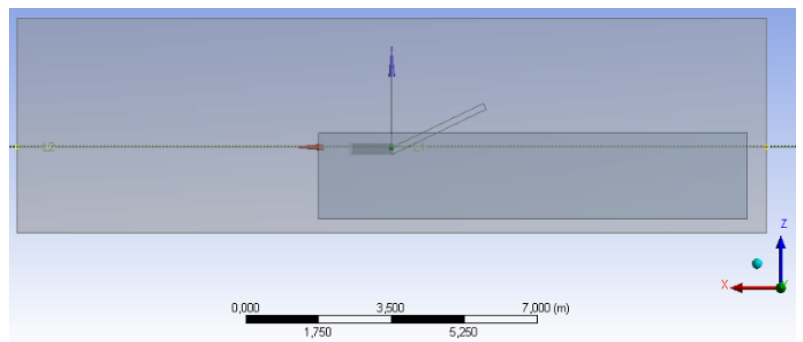

(a)

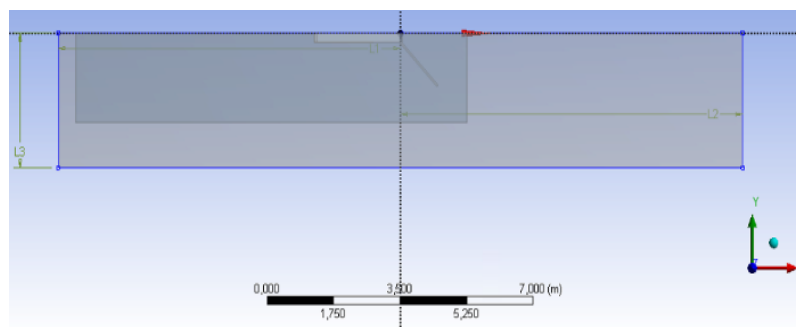

(b)

Fig. 2. Numerical tunnel (a) top view, (b) side view.

\subsection{Solver parameter}

A summary of the solver settings is given in table 2 . This setting process is the process of entering the parameter of tunnel and fluid in numerical simulation. The process includes models, materials, cell zone conditions, boundary conditions, mesh interfaces, dynamic mesh, reference values, solution methods, 
solution controls, solution initialization, calculation activities, and the last is run the calculation.

Table 2. Solver parameters used in the simulation

\begin{tabular}{|l|l|}
\hline Options & Single precision \\
\hline Processing option & parallel \\
\hline Processor & 5 \\
\hline GPU & 1 \\
\hline Solver & $3 \mathrm{D}$, Steady, implicit \\
\hline Type & Pressure base \\
\hline Gravity & $9.81 \mathrm{~m} / \mathrm{s}^{2}$ (z axis) \\
\hline Turbulence model & K-epsilon (2 eqn), standard \\
\hline Multiphase Model & $\begin{array}{l}\text { Volume of fluid, open } \\
\text { channel flow, implicit, } \\
\text { implicit body force }\end{array}$ \\
\hline Phase 1 & air \\
\hline Phase 2 & water liquid \\
\hline Inlet & Pressure inlet, multiphase \\
\hline Multiphase & Phase 2 \\
\hline Outlet & Pressure inlet,multiphase \\
\hline $\begin{array}{l}\text { Wall } \\
\text { treatment }\end{array}$ & $\begin{array}{l}\text { One layer all wall y+ } \\
\text { treatment }\end{array}$ \\
\hline Pressure-velocity coupling & Coupled \\
\hline Time discretization & First-order upwind \\
\hline Initialization & standard initialization \\
\hline From & inlet \\
\hline Open channel & flat \\
\hline Timescale factor & 0.5 \\
\hline Number of iteration & 2000 \\
\hline
\end{tabular}

\subsection{Convergence and grid independence}

Domain computation and winged conveyor model using structured hexahedral as shown in Fig. 3. Then, tested numerical results have been obtained-test conduct by using a different number of elements. The difference of elements number is approximately 1.5 until 2 times from the previous calculation [15]. Grid independence test is carried out to get optimal between cells number and solver running time. It is due to the limitations of the computer processor used in the solver calculation. Then, the error tolerance or difference between one result and the next is below $5 \%$.

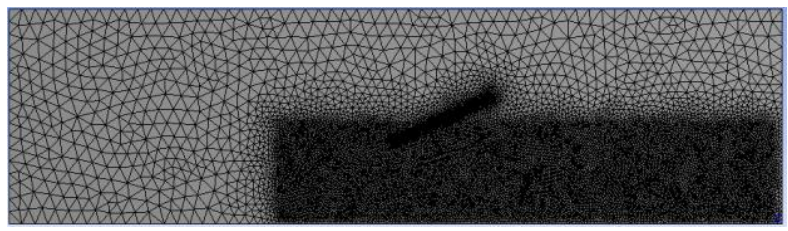

(a)

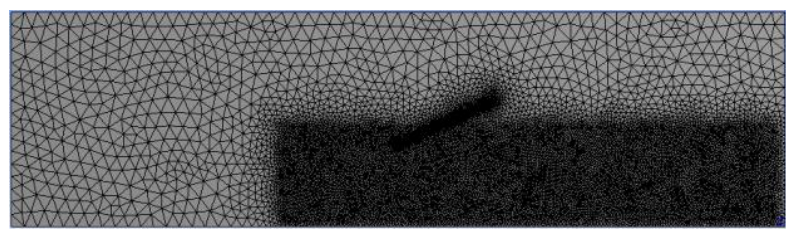

(b)

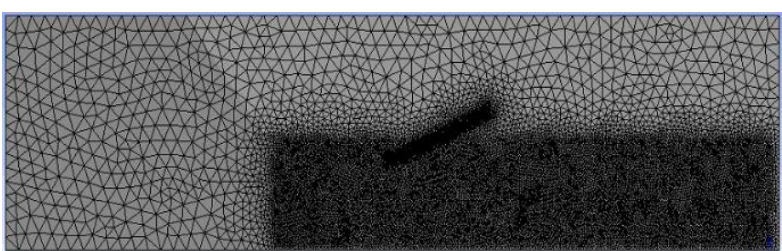

(c)

Figure 3. Side view of mesh generate in the computational domain: (a) solid wing, (b) square hollow wing, and (c) circle hollow wing

The root-mean-square (RMS) criteria were used to check the convergence with a residual target value (variable value) reaching 10-5. These residual monitors demonstrate monotonic convergence, indicating a wellposed problem and a tightly converged solution.

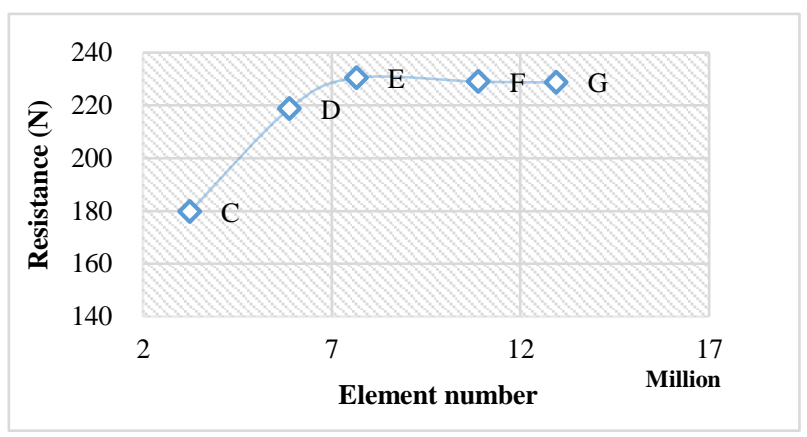

Fig. 4. Grid independence

Simulation of meshing stage of the winged conveyor using global body sizing of $0,05 \mathrm{~m}, 0,04 \mathrm{~m}$, $0,037 \mathrm{~m}, 0,035 \mathrm{~m}$, and 0,03 . The winged conveyor using face sizing of $0,05 \mathrm{~m}, 0,03 \mathrm{~m}, 0,02 \mathrm{~m}$, and $0,01 \mathrm{~m}$ around the hull results in the number of elements 3242232 , 5882419, 7653085, 10880693, 12941485 from the meshing simulation results using computational fluid dynamic. The selection of the number of meshing through the independence study approach grid is shown in Fig.4. Grid independence studies showed that optimal winged conveyor model simulations on grid number 7653085 have a half total resistance of $230,423 \mathrm{~N}$ to optimal difference resistance of $1 \%$

\section{Result and Discussion}

The results obtained are velocity contours, flow patterns, and resistance on each winged conveyor type waste collection tool. Variations in speed are 1, 3, 6, 12 knots. Comparison of speed contours of three models at 1-knots speed in Fig. 5. The water area in front of the solid wing model has a dark blue colour, the hollow square wing has a light blue colour, and the hollow circle wing has a green colourt this speed, it can be seen that the hollow circle wing is faster in collecting waste, followed by the hollow square wing and solid wing. 

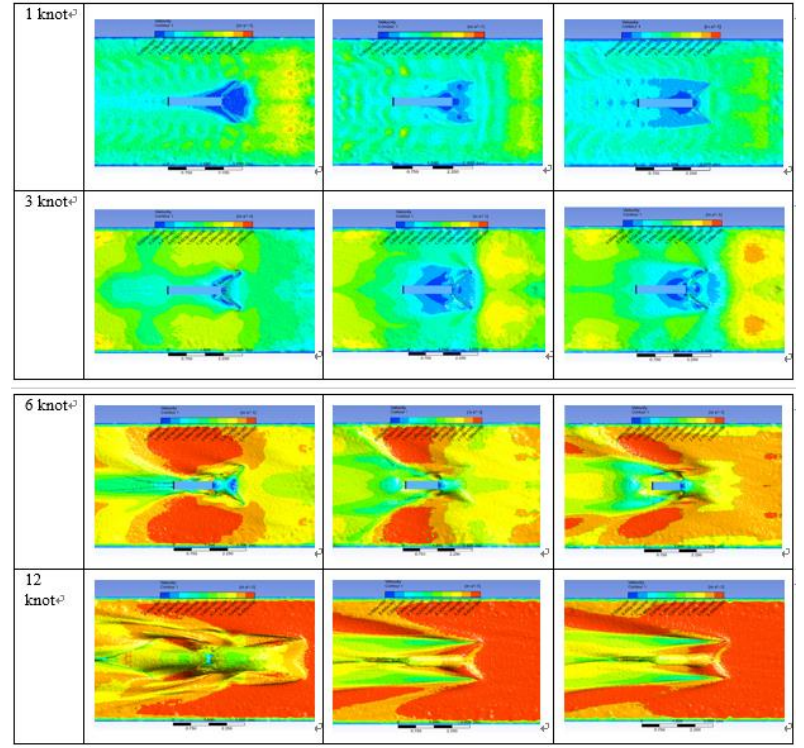

(a)

(b)

(c)

Figure. 5 Velocity contour: (a) solid wing, (b) square hollow wing, and (c) circle hollow wing

Meanwhile, from comparing 3-speed knots, it is known that the water passes through the winged conveyor in the circle hollow wing model. So it can't compare which one collects ocean waste the fastest at this speed. It is also seen at 6 knots and 12 knots, the water passes over the wings. The higher the speed, the higher the water that passes through it. So it also can't compare which one is the fastest to collect ocean waste at these two speeds. But it is known that winged conveyors can only be used to collect ocean waste at low speeds.
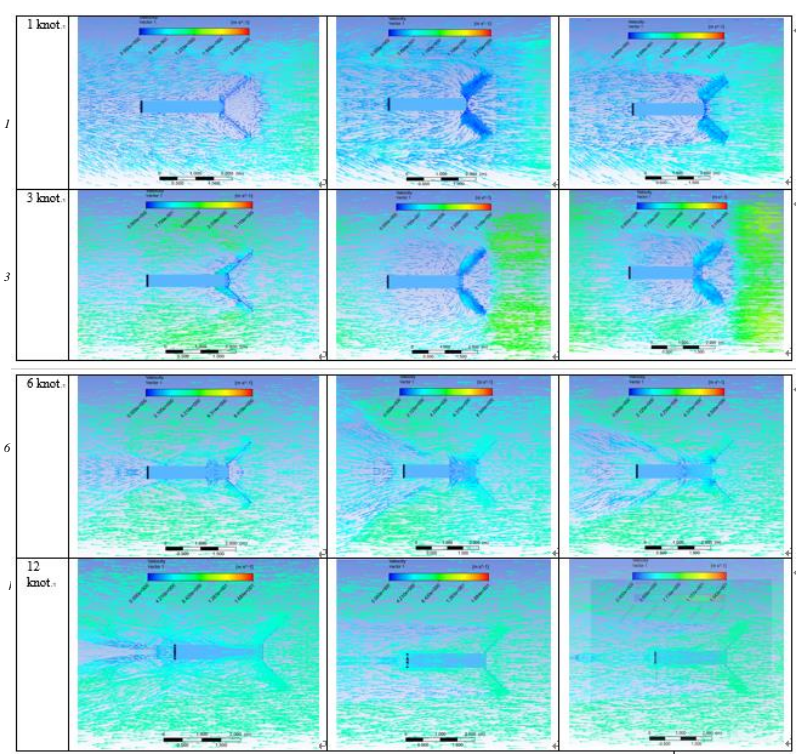

(a)

(b)

(c)

Fig. 6. Flow patterns: (a) solid wing, (b) square hollow wing, and (c) circle hollow wing

Base on the comparison of flow patterns of three models at 1-knots speed in Fig.6. It is known that the form of flow in front of the solid wing model has reverse flow after approaching the winged conveyor. This happens due to the wing is solid and water cannot flow through the wing. Meanwhile, the flow pattern in front of the square and circle hollow wing model can continue to flow through the wing because the cross-section of the wing is hollow. The flow pattern in front of the square and circle hollow wing model is almost the same. However, it can compare that the circle hollow wing model is easier to make waste closer to the winged conveyor than the square wing model. Furthermore, the colour of the flow line in front of the circle hollow wing model is a lighter blue than the square hollow wing model.

From comparing the 3 knots speed, it is known that the water passes through the winged conveyor in the circle hollow wing model. So it can't compare which one collects ocean waste the easiest at this speed. It is also seen at 6 knots and 12 knots, the water passes over the wings. So it can't compare which one collects ocean waste the easiest at those speeds.

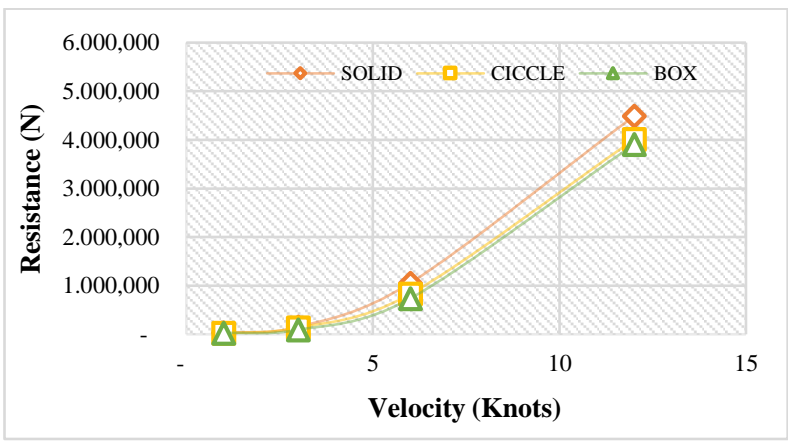

Figure 7. Comparison of resistance between solid wing, hollow square wing, and hollow circle wing in a simple conveyor at various velocity

From comparison in Fig.7, it can be seen that the greater the speed, the greater the resistance, although the comparison is not linear. It is also known that the resistance of winged conveyors from the largest to the smallest is the solid wing, hollow circle wing, and hollow square wing, respectively. For example, the difference in resistance at 9 knots between the circular hollow wing and square hollow wing is $1.99 \%$, the difference in resistance between the solid wing and square wing is $14.3 \%$. The Reynolds number was used to validate this simulation. Reynolds number is a parameter that can be used to determine the type of fluid around an object. In general, there are three types of flow in fluids, namely laminar, transitional, and turbulent. Based on Fig.7, it is known that all types of winged conveyors and all speeds will produce turbulent flow behind the model [16].

\section{Conclusion}

Based on the analysis of velocity contour, the hollow circle wing is faster in collecting waste, followed by the hollow square wing and solid wing. 
From the flow pattern analysis, the circle hollow wing model makes waste more easily to the winged conveyor than the square wing model. Meanwhile, the solid wing model has reverse flow after approaching the winged conveyor. This happens because the wing is solid and water cannot flow through the wing. It is also known that water passes through the winged conveyor in the circle hollow wing model at the 3 knots speed. So it can't compare which one collects ocean waste the fastest and the easiest at this speed. It is also seen at 6 knots and 12 knots, the water passes over the wings.

So it can't compare which one collects ocean waste the fastest and the easiest at those speeds. But it is known that winged conveyors can only be used to collect ocean waste at low speeds. Then based on resistance comparison, it can be seen that the greater the speed, the greater the resistance, although the comparison is not linear. It is also known that the resistance of winged conveyors from the largest to the smallest is the solid wing, hollow circle wing, and hollow square wing, respectively.

\section{Acknowledgements}

This paper was supported by a doctoral scholarship from the Taiwan government, CTCI Foundation Taiwan, and Universitas Hang Tuah Grant. The authors also would like to thank the Fisheries and Marine Science Faculty and MEAL Lab. (Marine Research Laboratory), Universitas Padjadjaran.

\section{References}

1. P. Vriend, H. Hidayat, J.V. Leeuwen, M.R. Cordova, N.P. Purba, A. J. Lohr, I. Faizal, N.S. Ningsih, K. Agustina, S. Husrin, D.D. Suryono, I. Hantoro, B. Widiarko, P. Lestari, B. Vermeulen, and T.V. Emmerik, Frontiers in Environmental Science 9, 1 (2021).

2. S. Miyagi, H. Saito, M. Ogido, K. Fujikura, S. Chiba, T. Yogi, R. Fletcher, and M. Kayo, Marine Policy 96, 204 (2018).

3. M. Bergmann, M. B. Tekman, and L. Gutow, Nature 544, 297 (2017).

4. N. P. Purba, D. I. W. Handyman, T. D. Pribadi, A. D. Syakti, W. S. Pranowo, A. Harvey, and Y. N. Ihsan, Marine Pollution Bulletin 146, 134 (2019).

5. UNEP \& GRID, Marine Litter Vital Graphics. United Nations Environment Programme and GRID-Arendal. Nairobi and Arendal. www.unep.org (2016).
6. O. Hoegh-Guldberg, R. Cai, E. S. Poloczanska, P. G. Brewer, S. Sundby, K. Hilmi, V. J. Fabry, and S. Jung, Climate Change 2014: Impacts, Adaptation and Vulnerability: Part B: Regional Aspects: Working Group II Contribution to the Fifth Assessment Report of the Intergovernmental Panel on Climate Change 1655 (2015).

7. J. R. Jambeck, R. Geyer, C. Wilcox, T. R. Siegler, M. Perryman, A. Andrady, R. Narayan, and K. L. Law, Climate Change 2014: Impacts, Adaptation and Vulnerability: Part B: Regional Aspects: Working Group II Contribution to the Fifth Assessment Report of the Intergovernmental Panel on Climate Change 1655 (2015).

8. E. Sugianto and J. H. Chen, in Indonesian Creativity, Ingenuity, and Innovation in a World in Transition, edited by F. Dhont, First Edit (Center of Multi-cultural Studies, National Cheng Kung University, Tainan, 2020), pp. 67-90.

9. E. Sugianto and J. H. Chen, in 33th Asian-Pacific Technical Exchange and Advisory Meetings on Marine Structures (TEAM 2020) (Tainan, 2019), p. S-27.

10. E. Sugianto and J. H. Chen, International Journal of Humanities and Social Sciences 3, 36 (2021).

11. Y. S. Deddy Chrismianto, Berlin Arswendo A, Kapal 11, 99 (2014).

12. C. Dwi, U. Budiarto, and G. Rindo, Kapal 3, 193 (2015).

13. A. I. W. Wulandari, W. S. Setiawan, T. H. Hidayat, and A. F. Fauzi, Wave: Jurnal Ilmiah Teknologi Maritim 14, 9 (2020).

14. H. K. Versteeg and W. Malalasekera, An Introduction to Computational Fluid Dynamics The Finite Volume Method, 2nd ed. (Pearson Education Limited, England, 2007).

15. Anderson, Computational Fluid Dynamics: The Basics with Applications. (1995).

16. United States Navy, Resistance and Powering of Ships (2002). 